\title{
Gene interactions and modifiers in epilepsy
}

\author{
Miriam H. Meisler \\ Department of Human Genetics, University of Michigan, Ann Arbor, Michigan, U.S.A.
}

\section{SUMMARY}

The onset, progression, and severity of epilepsy vary between family members with identical mutations in primary disease genes. The background of genetic variation unique to each individual genome contributes to clinical variation. Known examples of gene interactions in human families and mouse models provide insight into underlying molecular mechanisms. For an expanded treatment of this topic see Jasper's Basic Mechanisms of the Epilepsies, Fourth Edition (Noebels JL, Avoli M, Rogawski MA, Olsen RW, Delgado-Escueta AV, eds) published by Oxford University Press. (available on the National Library of Medicine Bookshelf [NCBI] at www. ncbi.nlm.nih.gov/books).

KEY WORDS: Coding variants, Genetic background, Seizures, Sodium channel, SCNIA.
During the last decade, the genetic basis for many seizure disorders has been identified by positional cloning of Mendelian genes segregating in large pedigrees, and by sequencing of candidate genes in sporadic cases and small families. More than 700 different mutations in the sodium channel gene SCN1A have been identified by these methods (Claes et al., 2009). It is now clear that different mutations in the same gene can produce disorders that were previously considered to be different entities (Meisler \& Kearney, 2005). Null mutations in SCN1A result in the severe sporadic disorder Dravet's syndrome, whereas missense mutations in the same gene produce the mild inherited syndrome known as generalized epilepsy with febrile seizures plus (GEFS+). However, even in individuals carrying the same sodium channel mutation, the clinical course can vary dramatically (Catterall et al., 2008). Genetic analysis in mouse models has revealed that strain background can influence the phenotypic expression of a disease mutation through the combined effects of many genetic differences between the parental strains. If the effects of modifier genes are sufficiently large, they may be identified by positional cloning in crosses between inbred strains. Another approach to identify genetic modifiers is to test directly for gene interactions by breeding mice that carry two epileptogenic mutations. Several examples of genetic interactions between mutations in different ion channel genes have been described. The recent advent of individual human genome sequencing has demonstrated that we each carry hundreds of very rare coding variants that change the amino acid sequences of cellular proteins. As genome sequences become part of medical records, information regarding genetic interactions and modifier genes will be applied to develop better diagnosis, prognosis, and treatment for patients with seizure disorders.

\section{Disclosure}

The author declares no conflict of interest.

\section{REFERENCES}

Catterall WA, Dib-Hajj S, Meisler MH, Pietrobon D. (2008) Inherited neuronal ion channelopathies: new windows on complex neurological diseases. J Neurosci 28:11768-11777.

Claes LRF, Deprez L, Suls A, Baets J, Smets K, Van Dyck T, Deconinck T, Jordanova A, De Jonghe P. (2009) The SCN1A variant database: a novel research and diagnostic tool. Hum Mutat 30:E904-E920.

Meisler MH, Kearney JA. (2005) Sodium channel mutations in epilepsy and other neurological disorders. J Clin Invest 115:2010-2017. 